\title{
Revisional Cochlear Implant Surgeries in Adults
}

\author{
Maria Stella A. Amaral' ${ }^{1}$, Henrique F. Pauna1, Eduardo T. Massuda'1, Ana Claudia M. B. Reis ${ }^{2}$, \\ Miguel A. Hyppolito ${ }^{1}$
}

\author{
${ }^{1}$ Department of Ophthalmology, Otorhinolaryngology and Head and Neck Surgery, Ribeirão Preto Medical School/University of \\ São Paulo, São Paulo, Brazil \\ ${ }^{2}$ Department of Health Sciences, Ribeirão Preto Medical School/University of São Paulo, São Paulo, Brazil \\ Email: stella_arantes@yahoo.com
}

How to cite this paper: Amaral, M.S.A., Pauna, H.F., Massuda, E.T., Reis, A.C.M.B., and Hyppolito, M.A. (2019) Revisional Cochlear Implant Surgeries in Adults. Advances in Bioscience and Biotechnology, 10, 259-269.

https://doi.org/10.4236/abb.2019.109020

Received: August 9, 2019

Accepted: September 15, 2019

Published: September 18, 2019

Copyright $\odot 2019$ by author(s) and Scientific Research Publishing Inc. This work is licensed under the Creative Commons Attribution International License (CC BY 4.0).

http://creativecommons.org/licenses/by/4.0/

(c) (i) Open Access

\begin{abstract}
Introduction: Cochlear implant (CI) surgery allows hearing reestablishment among individuals with severe to profound hearing loss. However, only few patients will need a surgical reassessment. Objectives: To verify the incidence of surgical reassessment among adult patients; to verify the reasons that led the second surgery to be performed; to verify the efficacy-and audiological outcomes-of revisional surgery. Method: A longitudinal retrospective cohort study was carried out with the review of medical records, of adult patients, with bilateral severe to profound sensorineural hearing loss who underwent to revisional surgery, from 2004 to 2016 at a CI Center, in Brazil. Results: One hundred fifty-eight CI surgeries were performed among 137 adult patients. Fourteen revisional surgeries were performed among 10 patients: five surgeries were due by displacement of the internal unit; one because of having excessive subcutaneous tissue; one due to non-progression of the electrodes during the initial surgery, one late tympanic membrane perforation, one late facial palsy and, one due to a suture dehiscence in the surgical incision with exposure of the internal unit. Conclusions: The incidence of surgical reassessment among adult CI patients was $8.9 \%$. All implanted patients that underwent a new surgical approach maintained an improved auditory threshold after revisional CI surgery.
\end{abstract}

\section{Keywords}

Cochlear Implants, Sensorineural Hearing Loss, Deafness, Revisional Surgery

\section{Introduction}

Cochlear implant (CI) is a surgically implanted prosthesis that is able to reestablish auditory function among patients with severe to profound hearing loss. The 
criteria to perform this surgery is expanding over the years, since the prevalence rates of hearing loss are increasing-mostly because of the populational increase-leading to a greater awareness that CI is the treatment of choice for deafness [1] [2].

Following to this increasing number of CI surgeries, an increasing number of revisional surgeries are observed, because of internal device failure (hardware or software), factors related to the etiology of hearing loss, or factors related to the surgery [1]. Exposition of the internal device or electrode, infection of the CI, and migration of the internal device are known to be frequent factors to lead to revisional surgery [3].

The CI revision surgery is uncommon, a small percentage of $3 \%-8 \%$ of all cochlear implant procedures requires the revisional surgery and cochlear reimplantation may be necessary for a variety of reasons. When this occurs, a common indication is hard failure, in about $40 \%-80 \%$ of the total cases of the CI reoperated. In most of the cases reoperation is performed by the explantation of the first device with immediate, at the same surgery procedure, or delayed reimplantation. In the cases of other common indications including soft failures, wound complications, infection, improper initial placement, and electrode extrusions, the revisional surgery could be performed only to scalp flap revision and receiver-stimulator repositioning, in the case of device migration. In cases of infection removing receiver-stimulator maintaining intracochlear electrodes is performing, with delayed reimplantation of a new device [3] [4].

Some surgical procedures could be necessary like the superior temporal fascia flap, auricle cartilage, and a deep temporal muscle flap can repair the defect in the posterior wall of the ear canal and cover the electrode in cases of partly or entirely be extruded from the cochlea or placed inappropriately electrodes and fixation of the internal receiver-stimulator can reduce the risk for device migration. For these cases, the revisional surgery using the same device requires maintaining the good results and good outcomes in speech perception tests. CI revisional surgery has a high rate successful on preservation or improvement of preoperative performance [5] [6] [7] [8].

Surgeons could consider using intraoperative imaging guidance like Conebeam-CT that could ensure the correct placement of electrodes in cases of severe inner ear malformation [8] [9].

Literature supposes that the surgery is well tolerated with high potential for restoration or improvement the speech perception. CI revisional surgery has become an important tool for the management of CI complications. Although are rare, surgeon must discuss the potential complications of revision surgery and their implications with patients and their families [9]-[14].

Although many reports in the literature indicate good auditory outcomes after revisional CI surgeries (which helps to define diagnostic criteria for device failure, as well as the criteria for reimplantation and expected outcomes after reimplantation surgery), there are also reports describing revisional CI surgery fault, with decreased electrode stimulation capacity, decreased speech perception, and 
associated intracochlear trauma [2] [4] [5] [6]. This should be considered when the surgical team is facing a candidate for revisional CI surgery.

The objective of the present study was to establish the incidence of revisional CI surgeries among adults, the reasons for revisional surgery, and auditory outcomes after surgery. Furthermore, we aimed to correlate the etiology of hearing loss, and the auditory outcomes after the secondary approach to support the indication for this surgery.

\section{Materials and Methods}

The present study was approved by the Institutional Review Board (CAAE: 824155118.9.0000.5440).

This is a longitudinal retrospective cohort study. Patients with bilateral, severe to profound hearing loss, older than 18 years of age, that underwent to a CI surgery from 2004 to 2016 were evaluated. Medical records were reviewed and data regarding age at the moment of implantation, sex, etiology of hearing loss, auditory outcomes before and after the revisional surgery (including data past one year of the secondary approach), and the reasons that led to revisional surgery were collected.

We recorded and compared speech perception performance with the initial device before the revision CI surgery and the performance between 3 and 6 months after revision CI surgery using the same speech perception tests. Speech perception testing was completed in an implant-only condition in sound field without use of a contralateral hearing aid. To this analysis, pre- and postoperative stages of the revisional CI surgery were applied with the nonparametric Wilcoxon irregular signaling test.

Information on type of surgery performed during revisional surgery was also collected. Data on CI electrode and manufacturer, as well hearing levels and speech perception tests, pre- and post-operatively were also collected.

Patients with central nervous system disorders as the etiology of deafness, prior middle or inner ear surgery, missing information or auditory assessment in their medical records were excluded.

\section{Statistical Analysis}

JMP SAS software version 10 (SAS Institute Inc., Cary, NC, USA) was used for statistical analysis. Quantitative variables were presented by means \pm standard deviation (SD), while qualitative variables were presented by frequency and percentage. The comparative tests between the pre- and postoperative stages of the revisional CI surgery were applied with the nonparametric Wilcoxon irregular signaling test. A significance level of $5 \%$ was adopted $(p<0.05)$.

\section{Results}

A total of 158 CI surgeries were performed from 2004 to 2016. Among these surgical CI procedures, 7 (5.1\%) were bilateral cochlear implantation, and 10 
(7.2\%) patients underwent to revisional surgery. In some patients more than one revisional surgery procedure was performed and a total of 14 revisional CI surgeries were performed among those 10 patients. The incidence of revisional surgeries was $8.9 \%$ (Table 1 ).

Of the 10 patients who required revisional CI surgery, 4 were male and 6 were female. Mean age of patients submitted to cochlear implantation was $47.0 \pm 11.3$ years, while the mean age of patients that underwent to revisional CI surgery was $47.4 \pm 11.3$ years. The internal unit was implanted in the right ear among 7 of these patients; in the left ear among 2 of the patients; and 1 patient was implanted with binaural CI (with the electrodes positioned in both ears).

None of the patients needed to change the side at the time of revisional surgery due to technical impossibility or contraindication of implantation on the same side of the first implant (Table 2).

Revisional surgery was performed among 5 patients due to the displacement of the internal unit; one patient presented excessive subcutaneous tissue over the internal unit; no full insertion of the electrodes was achieved in one patient; one patient presented a tympanic membrane perforation after first surgery; one patient presented facial palsy; and one patient presented dehiscence of surgical incision followed of exposition of internal unit.

Repositioning of the internal unit was necessary for 6 of the revisional CI surgeries. One case (patient 4) underwent two surgeries to reposition the internal unit.

One case (patient 7) underwent two tympanoplasties. One case (patient 1) underwent to excessive subcutaneous tissue removal, aiming to improve magnet effectiveness. There was a need of repositioning the electrodes in one case (patient 5).

One facial nerve decompression was necessary (patient 10). Lastly, one patient underwent to resuture of the surgical wound followed by explant and re-implantation of the internal unit during the same surgery (patient 6, in Table 3).

Table 4 shows the models of implanted devices: two from Oticon/Neurelec ${ }^{\circledR}$ (Saphyr and Saphyr binaural models), four from Advanced Bionics ${ }^{\circledR}$ (HiFocus model), and four Cochlear ${ }^{\circledR}$ (CI24 model). Patients 3 and 6 also had to change their CI electrodes and models when revisional surgery was performed.

Table 1. Distribution of cochlear implant (CI) surgeries performed between 2004 and 2016.

\begin{tabular}{ccc}
\hline Total number of CI patients & N & $\%$ \\
\hline Number of patients submitted to bilateral CI surgery & 137 & 100 \\
Number of patients submitted to revisional CI surgery & 7 & 5.1 \\
Total number of CI surgeries & 10 & 7.2 \\
Number of revisional surgeries & 158 & 100 \\
\hline
\end{tabular}


Table 2. Epidemiological data $(\mathrm{CI}=$ cochlear implant; $\mathrm{F}=$ female; $\mathrm{M}=$ male; $\mathrm{SD}=$ standard deviation).

\begin{tabular}{cccccc}
\hline Patient & Sex & $\begin{array}{c}\text { Age at the } \\
\text { time of CI } \\
\text { surgery (years) }\end{array}$ & $\begin{array}{c}\text { Age at the time of } \\
\text { revisional surgery } \\
\text { (years) }\end{array}$ & Implanted ear & $\begin{array}{c}\text { Implanted ear at } \\
\text { the revisional } \\
\text { surgery }\end{array}$ \\
\hline 1 & M & 44.7 & 44.8 & Right & Right \\
2 & F & 23.7 & 24.0 & Right & Right \\
3 & M & 43.2 & 44.7 & Left & Left \\
4 & F & 48.2 & 48.8 & Right & Right \\
5 & M & 37.1 & 37.2 & Right & Right \\
6 & F & 42.8 & 42.9 & Left & Left \\
7 & F & 60.4 & 61.0 & Right & Right \\
8 & F & 54.8 & 55.0 & Right & Right \\
9 & M & 56.0 & 56.2 & Binaural, processorBinaural, processor \\
on the left
\end{tabular}

Table 3. Description, case by case, of the number of surgeries performed, the reason for the revisional surgery, and type of revisional surgery performed $(\mathrm{CI}=$ cochlear implant; $\mathrm{MRI}=$ magnetic resonance image).

\begin{tabular}{|c|c|c|c|}
\hline Patient & $\begin{array}{c}\text { Number of revisional } \\
\text { CI surgeries }\end{array}$ & Cause of revisional surgery & Surgery performed \\
\hline 1 & 1 & Excessive subcutaneous tissue & $\begin{array}{l}\text { Removal of excessive } \\
\text { subcutaneous tissue }\end{array}$ \\
\hline 2 & 1 & Internal unit shift & Repositioning of the internal unit \\
\hline 3 & 1 & $\begin{array}{l}\text { Internal unit shift seen in } \\
\text { MRI }\end{array}$ & Repositioning of the internal unit \\
\hline 4 & 2 & Traumatic internal unit shift & Repositioning of the internal unit \\
\hline 5 & 1 & $\begin{array}{l}\text { Non-progression of } \\
\text { electrodes in surgery }\end{array}$ & Repositioning of the electrodes \\
\hline 6 & 3 & $\begin{array}{l}\text { Suture dehiscence and } \\
\text { exposition of the internal unit }\end{array}$ & Suture; explant; second CI surgery \\
\hline 7 & 2 & $\begin{array}{l}\text { Tympanic membrane } \\
\text { perforation }\end{array}$ & Tympanoplasty \\
\hline 8 & 1 & Internal unit shift & Repositioning of the internal unit \\
\hline 9 & 1 & Internal unit shift & Repositioning of the internal unit \\
\hline 10 & 1 & Facial palsy & Facial nerve decompression \\
\hline Total & 14 & & \\
\hline
\end{tabular}

Regarding the etiology of hearing loss, three were due to trauma, two were due to meningitis, two were due to otosclerosis, one patient was deaf due to ototoxicity, and in two patients it was idiopathic (Table 5). There was an improvement in mean auditory thresholds after one year of revisional surgeries, from 
Table 4. Description of Cochlear Implant (CI) company and model, for both first surgery and revisional surgery.

\begin{tabular}{|c|c|c|c|}
\hline Patient & Cochlear implant & CI exchange & $2^{\text {nd }}$ cochlear implant \\
\hline 1 & Oticon/Neurelec ${ }^{\circledR}$ EVO & No & - \\
\hline 2 & $\mathrm{AB}^{\circledR}$ HiFocus & No & - \\
\hline 3 & $\mathrm{AB}^{\circledR}$ HiFocus & Yes & Cochlear Freedom \\
\hline 4 & Cochlear $^{\circledR}$ CI24RCA & No & - \\
\hline 5 & Cochlear ${ }^{\circledR}$ CI24RCA & No & - \\
\hline 6 & $\mathrm{AB}^{\circledR}$ HiFocus MidScala & Yes & Cochlear CI422 \\
\hline 7 & Cochlear $^{\circledR}$ CI24RCA & No & - \\
\hline 8 & Cochlear ${ }^{\circledR}$ CI24RCA & No & - \\
\hline 9 & Oticon/Neurelec ${ }^{\circledR}$ Binaural & No & - \\
\hline 10 & $\mathrm{AB}^{\circledR}$ HiFocus & No & - \\
\hline
\end{tabular}

Table 5. Mean auditory thresholds, pre-operative and post-revisional surgery $(\mathrm{dB} H \mathrm{HL}=$ decibel hearing level).

\begin{tabular}{cccc}
\hline Patient & Etiology & $\begin{array}{c}\text { Mean hearing level } \\
\text { pre-CI (dB HL) }\end{array}$ & $\begin{array}{c}\text { Mean hearing level after } \\
\text { revisional surgery (dB HL) }\end{array}$ \\
\hline 1 & Meningitis & 116.25 & 41.25 \\
2 & Meningitis & 111.25 & 40 \\
3 & $\begin{array}{c}\text { Surgical trauma } \\
\text { (pineal tumor removal) }\end{array}$ & 120 & 25 \\
4 & Idiopathic progressive & 101.25 & 36.25 \\
5 & Idiopathic progressive & 98.75 & 30 \\
6 & Trauma & 106.25 & 25 \\
7 & Otosclerosis & 120 & 25 \\
8 & Idiopathic progressive & 116.25 & 23.75 \\
9 & Trauma & 114.37 & 38.75 \\
10 & Ototoxicity & 120 & 46.25 \\
Mean hearing level & & $112.4 \pm 7.9$ & $33.1 \pm 8.3$ \\
\hline
\end{tabular}

$112.4 \mathrm{dBHL}$ to $33.1 \mathrm{dBHL}$, among the frequencies of 500,1000, 2000 and 4000 $\mathrm{Hz}(p=0.002)$. Lastly, there was an improvement in speech perception for trisyllables in an open set, from $20.2 \%$ to $83.2 \%(p=0.002$; Table 6$)$.

\section{Discussion}

In this study, the incidence of revisional CI surgery was $8.9 \%$, similarly to Wang et al. [7], for both children and adults, with an incidence rate of $8.3 \%$. But Sunde et al. [8] found a revisional surgery rate of $3 \%$ in adults. The literature shows the incidence rates from $1.2 \%$ to $14.7 \%$ of revisional CI surgeries. This variability can be explained by the characteristics of the sample and the period of study, 
Table 6. Speech perception tests pre-operatively and post-revisional surgery.

\begin{tabular}{ccc}
\hline Patient & Prior to first surgery (\%) & Post-revisional surgery (\%) \\
\hline 1 & 0 & 100 \\
2 & 0 & 88 \\
3 & 0 & 88 \\
4 & 44 & 60 \\
5 & 64 & 90 \\
6 & 4 & 72 \\
7 & 0 & 88 \\
8 & 80 & 100 \\
9 & 0 & 70 \\
10 & 10 & 76 \\
Mean \pm SD & $20.2 \pm 30.7$ & $83.2 \pm 13.2$ \\
\hline
\end{tabular}

considering the failure of the hardware and software of the internal unit, and considering the technological improvements of the internal units, currently available in the worldwide [9] [10].

The indication criteria for unilateral CI surgery was based on anatomical criteria, when assessed by imaging exams and audiological results, being considered the worst auditory residue, which would allow a bimodal hearing to the patient after CI surgery.

Thus, seven patients were implanted on the right side, two on the left side and one binaural IC patient (Table 2), in accordance with the literature so far [11] [12]. During the revisional surgery there was no indication to implant the contralateral side, unlike what is reported in the literature, which shows a reimplantation rate of $85 \%$ on the same side of the original implant and $15 \%$ on the contralateral side, which can be explained by several factors such as evaluation period, experience of the implantation center and the surgeon, socio-cultural characteristics of the implanted population, and technological advances of the implanted internal units [7].

The most frequent reason for revisional CI surgery was the internal unit shift, which occurred in $50 \%$ of the cases, Three of them was related to the surgical technique with anterior displacement when used minimally invasive technique with the implant fixed only by the pocket, without fixing it to the bone of the skull or performing a bone niche to accommodate the internal device; one by mechanical trauma and one by an inadvertent exposure to magnetic resonance, not following the guidelines of the cochlear implant team and the manufacturer.

Wang et al. [7] reported that internal unit shift in $30 \%$ of cases (as the second most common reason for revisional CI surgery), while the main cause was the internal device failure (43.5\%). Zeitler et al. [13] reported a revisional CI surgery rate of $40 \%$ to $80 \%$ due to hardware or software failure, what was not found in this study. These studies argue that this type of failure has been progressively 
reduced considering the technological changes in the new cochlear implant generations, a tendency already shown by Côté et al. [14]. Because it is a recent center and work with the most modern technologic generations of cochlear implant, in this case there was no failure of the internal device related to the fabrication of the hardware. The failure of the hardware occurred in a single case but was caused by problems related to improper magnetic resonance imaging in the patient, this reinforces what has been demonstrated in the literature that the reduction in internal device (hardware) failure is related to improvement in the quality of the implanted device [7].

Nevertheless, there is a need to emphasize the guidance to CI users about the care with your CI electronic device, as well as the need to expand the knowledge of the care with cochlear implants to general health teams, mainly about the restrictions for certain medical interventions, health care and exams. There is consensus in the literature that when performing MRI, the professional must attend or be instructed to the use of bandages, the Tesla and that not all IC manufacturers offer a CI device that is compatible to MRI [14].

Post-CI monitoring to detect possible internal device failures is imperative, considering the number of children implanted earlier. Children also have a higher rate of device failure due to head trauma. The greatest difficulty that arises when very young children, implanted before a year of age, is to determine if the poor result is occurring due to failures in the internal device or due to biological issues related to the central auditory or integration pathways [14].

During surgery we found no fibrosis or cholesteatoma in the intraoperative period of the revisional surgery, differently of other studies that reported the presence of cholesteatoma-related to the erosion of the external auditory canal by the electrodes, by tympanic ring tearing during the first CI surgery, or by chronic middle ear infection in children. Even in the case of tympanic perforation, cholesteatoma was not found, probably because it was a central tympanic membrane perforation [9] [13] [14].

This study showed 10 causes for the revisional surgeries, six of them could be avoided, such as tympanic perforation (1 case), the displacement of the internal drive ( 3 cases), excessive subcutaneous tissue ( 1 case) and facial palsy ( 1 case), could be avoided by a more effective intervention of medical staff with training and intraoperative monitoring, which has been constant attention and investments of the medical team in reference and training hospitals, and in training for young surgeons who are beginning the practice for CI surgery, as is the case of our service-A university training hospital, with fellowship CI program [15].

In two of the cases (cases 5 and 6) who presented a non-progressive introduction of the electrodes in cochlea and another suture dehiscence and exposure of the external unit were considered causes of difficult control because all the pre, intra and post-operative cares were adopted [15] [16] [17] [18].

The posterior tympanotomy is a necessary procedure for adequate access of the facial nerve recess for adequate round window exposure. However, erosion of the external auditory canal may happen by excessive drilling of the posterior 
wall. This complication can be avoided with the application of bone patté, occluding the posterior tympanotomy, which was routinely performed in all cases within this cohort [4].

The depth of reinsertion of the electrodes is described as partial in $7 \%$ of the cases. Even if total insertion occurs in the first surgery, it may happen due to fibrosis or new bone formation inside the cochlear turns, resulting in reduction of the lumen of the scala tympani. Therefore, there is a wide variety of electrodes available, and the thinner and more straightened electrodes are mostly recommended in these cases. In this study, there was no difficulty in reinsertion of the electrode bundle, with complete reinsertion in all cases, even in the case of patient 5 (with a previous difficult inserting the electrodes at the first surgery).

The CI brands and models were not control variables in the present study. The reason why is that we considered the demand for their equal distribution in the Brazilian public health system, regarding all public CI Centers distributed in Brazil [17] [18] [19]. Thus, patients who needed revision surgeries were: four with the internal device of the brand Advanced Bionics ${ }^{\circledR}$, four from Cochlear ${ }^{\circledR}$ Company and two from Oticon/Neurelec ${ }^{\circledR}$ Company.

Cochlear implant replacement occurred in two subjects (20\%), and $80 \%$ of the cases did not require internal device replacement, which is linked to the literature reports, with $70 \%$ of cases of revisional surgeries not evolving to reimplantation with another brand device [20] [21].

The audiological results obtained by free-field audiometry show significant improvement after revisional surgery, when compared to pre-operatively results $(p=0.002)$. Speech perception tests for trisyllables after one year of revisional surgery were also significantly better when compared to the pre-operative period (Table 5 and Table 6), suggesting that revisional surgery did not change auditory outcomes in the present study. This result is aligned with the findings of Lassig et al. [4], Rivas et al. [5] and Sunde et al. [8], who obtained good audiological results in speech perception tests after revisional surgeries.

\section{Conclusion}

In the total number of CI surgeries between 2004 and 2016 in this Cochlear Implant Center, the incidence rate of revisional surgeries was $8.9 \%$, mainly because of internal unit shift. There was an improved audiological outcome in all cases-after the second surgery, which reinforces the benefit of revisional CI surgery, when necessary.

\section{Funding}

This study was funded by Coordenação de Aperfeiçoamento de Pessoal de Nível Superior (CAPES, code 001).

\section{Conflicts of Interest}

Authors declare they have no conflicts of interest. 


\section{References}

[1] Clark, G.M., Clark, J.C. and Furness, J.B. (2013) The Evolving Science of Cochlear Implants. JAMA, 310, 1225-1226. https://doi.org/10.1001/jama.2013.278142

[2] Reis, M., Boisvert, I., Looi, V. and da Cruz, M. (2017) Speech Recognition Outcomes after Cochlear Reimplantation Surgery. Trends in Hearing, 21.

https://doi.org/10.1177/2331216517706398

[3] Brown, K.D., Connell, S.S., Balkany, T.J., Eshraghi, A.E., Telischi, F.F. and Angeli, S.A. (2009) Incidence and Indications for Revision Cochlear Implant Surgery in Adults and Children. Laryngoscope, 119, 152-157. https://doi.org/10.1002/lary.20012

[4] Lassig, A.A., Zwolan, T.A. and Telian, S.A. (2005) Cochlear Implant Failures and Revision. Otology \& Neurotology, 26, 624-634. https://doi.org/10.1097/01.mao.0000178123.35988.96

[5] Rivas, A., Marlowe, A.L., Chinnici, J.E., Niparko, J.K. and Francis, H.W. (2008) Revision Cochlear Implantation Surgery in Adults: Indications and Results. Otology \& Neurotology, 29, 639-648. https://doi.org/10.1097/MAO.0b013e31817e5d31

[6] Henson, A.M., Slattery 3rd, W.H., Luxford, W.M. and Mills, D.M. (1999) Cochlear Implant Performance after Reimplantation: A Multicenter Study. American Journal of Otolaryngology, 20, 56-64.

[7] Wang, J.T., Wang, A.Y., Psarros, C. and Da Cruz, M. (2014) Rates of Revision and Device Failure in Cochlear Implant Surgery: A 30-Year Experience. Laryngoscope, 124, 2393-2399. https://doi.org/10.1002/lary.24649

[8] Sunde, J., Webb, J.B., Moore, P.C., Gluth, M.B. and Dornhoffer, J.L. (2013) Cochlear Implant Failure, Revision, and Reimplantation. Otology \& Neurotology, 34, 1670-1674. https://doi.org/10.1097/MAO.0000000000000079

[9] Buchman, C.A., Higgins, C.A., Cullen, R. and Pillsbury, H.C. (2004) Revision Cochlear Implant Surgery in Adult Patients with Suspected Device Malfunction. Otology \& Neurotology, 25, 504-510. https://doi.org/10.1097/00129492-200407000-00018

[10] Qiu, J., Chen, Y., Tan, P., et al. (2011) Complications and Clinical Analysis of 416 Consecutive Cochlear Implantations. International Journal of Pediatric Otorhinolaryngology, 75, 1143-1146. https://doi.org/10.1016/j.ijporl.2011.06.006

[11] Firszt, J.B., Holden, L.K., Reeder, R.M., Cowdrey, L. and King, S. (2012) Cochlear Implantation in Adults with Asymmetric Hearing Loss. Ear and Hearing, 33, 521-533. https://doi.org/10.1097/AUD.0b013e31824b9dfc

[12] Amaral, M.S.A.D., Damico, T.A., Gonçales, A.S., et al. (2018) Is There a Best Side for Cochlear Implants in Post-Lingual Patients? Brazilian Journal of Otorhinolaryngology, 84, 560-565. https://doi.org/10.1016/j.bjorl.2017.06.012

[13] Zeitler, D.M., Budenz, C.L. and Roland Jr., J.T. (2009) Revision Cochlear Implantation. Current Opinion in Otolaryngology \& Head and Neck Surgery, 17, 334-338. https://doi.org/10.1097/MOO.0b013e32832dd6ac

[14] Côté, M., Ferron, P., Bergeron, F. and Bussières, R. (2007) Cochlear Reimplantation: Causes of Failure, Outcomes, and Audiologic Performance. Laryngoscope, 117, 1225-1235. https://doi.org/10.1097/MLG.0b013e31805c9a06

[15] Vogl, T.J., Tawfik, A., Emam, A., et al. (2015) The Pre-, Intra- and Post-Operative Imaging of Cochlear Implants. RöFo, 187, 980-989. https://doi.org/10.1055/s-0035-1553413

[16] Bento, R.F., Brito, R.V. and Sanchez, T.G. (2001) Complicações da cirurgia do im- 
plante coclear. International Archives of Otorhinolaryngology, 5, 3.

[17] Portaria GM/MS No 1.278 de 20 de outubro de (1999) Aprova os critérios de Indicação e Contra-Indicação de Implante e as normas para Cadastramento de Centros/Núcleos para a realização de Implante Coclear. Brasília.

[18] Portaria GM/MS No 793 de 24 de abril de (2012) Institui a rede de cuidados à pessoa com deficiência no âmbito do Sistema Único de Saúde. Brasília, Seção 1, 94-95.

[19] Portaria GM/MS No 835 de 25 de abril de (2012) Institui incentivos financeiros de investimento e de custeio para o Componente Atenção Especializada da Rede de Cuidados à Pessoa com Deficiência no Âmbito do Sistema Único de Saúde. Brasília.

[20] Venail, F., Sicard, M., Piron, J.P., et al. (2008) Reliability and Complications of 500 Consecutive Cochlear Implantations. Archives of Otolaryngology_Head and Neck Surgery, 134, 1276-1281. https://doi.org/10.1001/archoto.2008.504

[21] Lescanne, E., Al Zahrani, M., Bakhos, D., Robier, A. and Moriniere, S. (2011) Revision Surgeries and Medical Interventions in Young Cochlear Implant Recipients. International Journal of Pediatric Otorhinolaryngology, 75, 1221-1224.

https://doi.org/10.1016/j.ijporl.2011.07.003 